\title{
The Effects of Nitrous Oxide on Controlled Hypotension During Low Flow Anesthesia
}

\author{
Semiha Barçın 1, Leyla Sahan 1, Dilsen Ornek* 1, Fazilet Sahin 1, Oya Kilci 1, \\ Serpil Deren ${ }^{1}$, Gulay Erdogan ${ }^{1}$, Canan Un ${ }^{1}$, Mehmet Gamli ${ }^{1}$, Bayazit Dikmen ${ }^{1}$
}

1. Anaesthesia and Reanimation Department, Ankara Numune Training and Research Hospital, Ankara, Turkey Received from the Anaesthesia and Reanimation Department, Ankara Numune Training and Research Hospital, Ulku Mahallesi Talatpasa Bulvari No: 5, Altindag, Ankara 06100, Turkey.

Submitted on December 26, 2011. Approved on February 13, 2012.

\author{
Keywords: \\ Hypotension, \\ Controlled; \\ Anesthesia, \\ Closed-Circuit; \\ Nitrous Oxide; \\ Dexmedetomidine.
}

\begin{abstract}
Background and objectives: We investigated the effect of Nitrous Oxide $\left(\mathrm{N}_{2} \mathrm{O}\right)$ on controlled hypotension in low-flow isoflurane-dexmedetomidine anesthesia in terms of hemodynamics, anesthetic consumption, and costs.

Methods: We allocated forty patients randomly into two equal groups. We then maintained dexmedetomidine infusion $\left(0.1 \mu \mathrm{g} \cdot \mathrm{kg}^{-1} \cdot \mathrm{min}^{-1}\right)$ for 10 minutes. Next, we continued it until the last 30 minutes of the operation at a dose of $0.7 \mu \mathrm{g} \cdot \mathrm{kg}^{-1}$. hour ${ }^{-1}$. We administered thiopental (4-6 mg. $\mathrm{kg}^{-1}$ ) and 0.08-0.12 mg. $\mathrm{kg}^{-1}$ vecuronium bromide at induction for both groups. We used isoflurane (2\%) for anesthesia maintenance. Group N received a $50 \% \mathrm{O}_{2}-\mathrm{N}_{2} \mathrm{O}$ mixture and Group A received $50 \% \mathrm{O}_{2}$-air mixture as carrier gas. We started low-flow anesthesia $\left(1 \mathrm{~L}\right.$. $\left.\mathrm{min}^{-1}\right)$ after a 10 -minute period of initial high flow $\left(4.4 \mathrm{~L} . \mathrm{min}^{-1}\right)$. We recorded values for blood pressure, heart rate, peripheral $\mathrm{O}_{2}$ saturation, inspiratory isoflurane, expiratory isoflurane, inspiratory $\mathrm{O}_{2}$, expiratory $\mathrm{O}_{2}$, inspiratory $\mathrm{N}_{2} \mathrm{O}$, expiratory $\mathrm{N}_{2} \mathrm{O}$, inspiratory $\mathrm{CO}_{2}, \mathrm{CO}_{2}$ concentration after expiration, Minimum Alveolar Concentration. In addition, we determined the total consumption rate of fentanyl, dexmedetomidine and isoflurane as well as bleeding.

Results: In each group the heart rate decreased after dexmedetomidine loading. After intubation, values were higher for Group A at one, three, five, 10, and 15 minutes. After intubation, the patients reached desired hypotension values at minute five for Group $\mathrm{N}$ and at minute 20 for group A. MAC values were higher for Group N at minute one, three, five, 10 , and $15(p<0.05)$. $\mathrm{FiO}_{2}$ values were high between minute five and 60 for Group A, while at minute 90 Group $N$ values were higher $(\mathrm{p}<0.05)$. Fi Iso (inspiratuvar isofluran) values were lower in Group $\mathrm{N}$ at minute 15 and $30(p<0.05)$.

Conclusion: By using dexmedetomidine instead of nitrous oxide in low flow isoflurane anesthesia, we attained desired MAP levels, sufficient anesthesia depth, hemodynamic stability and safe inspiration parameters. Dexmedetomidine infusion with medical air-oxygen as a carrier gas represents an alternative anesthetic technique.

๑ 2013 Sociedade Brasileira de Anestesiologia. Published by Elsevier Editora Ltda. All rights reserved.
\end{abstract}

*Corresponding author: Anaesthesia and Reanimation Department, Ankara Numune Training and Research Hospital, Ulku Mahallesi Talatpasa Bulvari No: 5, Altindag, Ankara 06100, Turkey. Telephone: 031250840 00; Fax: 03123114340.

E-mail: dilsenpinar@yahoo.com.

ISSN/\$ - see front metter ๔ 2013 Sociedade Brasileira de Anestesiologia. Published by Elsevier Editora Ltda. All rights reserved. 


\section{Introduction}

Controlled hypotension is a method used to improve the surgical environment by providing a dry area in middle ear surgery ${ }^{1}$. For this purpose, patient position and ventilation control can be supplemented with pharmacologic agents like vasodilators, beta-blockers, ganglion blockers and high dose potent inhalation anesthetics ${ }^{1-5}$.

For controlled hypotension, inhalation agents have potential benefits ${ }^{5}$, such as ease of administration and availability, hypotensive and anesthetic effects, and rapid clearance. Isoflurane decreases systemic vascular resistance and maintains cardiac output at normal levels, while reducing mean arterial pressure. However, in some patients rebound hypertension is observed, which prevents reflex sympathetic stimulation and maintenance of desired hypotension levels ${ }^{6}$. For this reason, additional medicines are often used to alleviate these adverse effects ${ }^{7-9}$.

Dexmedetomidine is a a2-adrenoceptor agonist used as a sedative, analgesic, and anxiolytic agent that affects heart rate and decreases arterial pressure. Dexmedetomidine is beneficial for controlled hypotension ${ }^{10}$.

In middle ear surgeries, when the tympanic membrane is placed the middle ear becomes a closed space and the membrane could detach from its original placement if nitrous oxide diffuses into this space. As such, nitrous oxide should be avoided during tympanoplasty or when cutting the graft before placement ${ }^{11}$. To avoid the harmful effects of nitrous oxide, inhalation anesthesia using low flow techniques and other agents can be used ${ }^{12}$.

The economic and ecological drawbacks of anesthetic gas use can be addressed using low flow anesthetic techniques. By using re-inspiration techniques at high levels, anesthetic gas consumption and pollution decreases to minimal levels, as the contamination of the operating room, while any harmful effects are not increased.

We investigated the effects of nitrous oxide in middle ear surgery patients using controlled hypotension created by dexmedetomidine and isoflurane in low flow anesthesia.

\section{Methods}

The Institution's ethics committee approved this study and informed consent was obtained from all patients. Forty patients of ages between 18 and 61 years and ASA I or ASA II physical status scheduled to undergo middle ear surgery were included in this prospective, randomized study. Patients with liver failure, diabetes mellitus, cardiovascular system pathology, anemia, drug allergies, bleeding disorders, or pregnancy were excluded, as were patients using medications affecting the coagulation system. All patients were included in the statistical evaluations and all completed the study. Leakage control of anesthesia circuits and gas monitor calibration was carried out before each operation. For each operation single use anesthesia circuits and bacteria filters were employed. The $\mathrm{CO}_{2}$ absorbent was changed daily.

We did not administer any premedication to the patients. We monitored electrocardiography (ECG), heart rate (HBR), noninvasive arterial blood pressure (NABP) and peripheral oxygen saturation $\left(\mathrm{SpO}_{2}\right)$ in the operating room with an $\mathrm{ADU}$ $\mathrm{S} / 5$ anesthesia device (Datex-Ohmeda, Finland). Intravenous vascular access (IV) was established via 18G (gauge) or 20G intravenous cannula and Ringer Lactate infusion initiated with a $5-10 \mathrm{~mL} . \mathrm{kg}^{-1}$. Preoxygenation was provided with $100 \% \mathrm{O}_{2}$ via face mask for ten minutes.

A $22 \mathrm{G}$ catheter was placed in the radial artery of the non-dominant hand for invasive blood pressure monitoring. After reading basal values, we started dexmedetomidine serum infusion ( $4 \mu \mathrm{g} \cdot \mathrm{mL}^{-1}$ in a total volume of $50 \mathrm{~mL}$ ). After dexmedetomidine infusion by injector type infusion pump for 10 minutes at a dose of $0.1 \mu \mathrm{g} \cdot \mathrm{kg}^{-1} \cdot \mathrm{min}^{-1}$, heart rate and blood pressure values were recorded. Dexmedetomidine infusion was continued until the last 30 minutes of the operation at a dose of $0.7 \mu \mathrm{g} \cdot \mathrm{kg}^{-1}$. hour ${ }^{-1}$.

For anesthesia induction, we administered 4-6 mg kg-1 thiopental (Pental Sodyum, İbrahim Ethem Ulagay İlaç Sanayi, İstanbul, Turkey) and 0.08-0.12 mg. $\mathrm{kg}^{-1}$ vecuronium bromide (Norcuron, Organon, Oss, Holland) until the thiopental wink reflex disappeared, after which we intubated the patient. After endotracheal intubation, we connected all patients to an ADU S/5 anesthesia device (Datex-Ohmeda, Finland) and maintained the tidal volume at $8-10 \mathrm{~mL}^{\mathrm{kg}} \mathrm{kg}^{-1}$ at 12 breaths. $\mathrm{min}^{-1}$. A gas analyzer monitor was used for all patients and soda lime (Sorbo-Lime ${ }^{\circledR}$ ) was used as a $\mathrm{CO}_{2}$ absorbent.

Patients were randomly assigned to two groups ( $\mathrm{N}$ and $\mathrm{A}$ ) using sealed envelopes chosen by the patients before the study. The fresh gas flow was as follows: $4.4 \mathrm{~L} \cdot \mathrm{min}^{-1}\left(\mathrm{O}_{2} / \mathrm{N}_{2} \mathrm{O}=1.4 / 3\right)$ containing $1.5 \%$ isoflurane after induction for providing denitrogenization and improving anesthesia. After 10 minutes, we reduced Group N $(n=20)$ fresh gas flow to $1 \mathrm{~L} \cdot \mathrm{min}^{-1} 50 \% \mathrm{O}_{2}$ in $\mathrm{N}_{2} \mathrm{O}$, providing $\mathrm{FiO}_{2}$ value above 0.30 and $2-2.5 \%$ isoflurane was administered. Twenty minutes before tympanic membrane placement, we stopped the nitrous oxide flow and isoflurane administration continued at $50 \% \mathrm{O}_{2}$ in air with $2-2.5 \%$ isoflurane. For Group A ( $n=20)$, after 10 minutes, fresh gas flow was reduced to $1 \mathrm{~L}$. $\min ^{-1} 50 \% \mathrm{O}_{2}$ in air providing a $\mathrm{FiO}_{2}$ value above 0.30 and $2-2.5 \%$ isoflurane was administered.

We chose the isoflurane concentration at values where the baseline MAP is decreased by $30 \%$ and was stopped 10 minutes before the end of the operation. Fresh gas flow at 6 L. min $^{-1}$ $100 \% \mathrm{O}_{2}$ was administered 5 minutes before the end of the operation. After extubation values were recorded, the patients were extubated. Heart rate (HR), mean arterial pressure (MAP), peripheral $\mathrm{O}_{2}$ saturation $\left(\mathrm{SpO}_{2}\right)$, inspiratory isoflurane ( $\mathrm{Fi}$ Iso), expiratory isoflurane (ETIso), inspiratory $\mathrm{O}_{2}\left(\mathrm{FiO}_{2}\right)$, expiratory $\mathrm{O}_{2}\left(\mathrm{ETO}_{2}\right)$, inspiratory $\mathrm{N}_{2} \mathrm{O}\left(\mathrm{FiN}_{2} \mathrm{O}\right)$, expiratory $\mathrm{N}_{2} \mathrm{O}\left(\mathrm{ETN}_{2} \mathrm{O}\right)$, inspiratory $\mathrm{CO}_{2}\left(\mathrm{FiCO}_{2}\right), \mathrm{CO}_{2}$ concentration after expiration $\left(\mathrm{ETCO}_{2}\right)$, Minimum Alveolar Concentration (MAC), respiratory tract plateau pressure (Pplato) values were recorded before and after dexmedetomidine loading, after zero, three, five, 10 , and 15 minutes after intubation at five minutes intervals to minute 60 and then at 15 minutes intervals. During surgery, monitors were adjusted so that the end tidal carbon dioxide $\left(\mathrm{ETCO}_{2}\right)$ was between $35-40 \mathrm{~mm} \mathrm{Hg}$ and $\mathrm{FiO}_{2}$ was above $30 \%$. When $\mathrm{ETCO}_{2}$ rose above $40 \mathrm{~mm} \mathrm{Hg}$, or $\mathrm{FiO}_{2}$ or $\mathrm{SpO}_{2}$ fell below $30 \%$ or 95 , respectively, fresh gas flow rate was increased to 4.4 L. $\mathrm{min}^{-1}$ and those patients were then excluded from the study.

Alfentanil was administered by IV at $7 \mu \mathrm{g} . \mathrm{kg}^{-1}$ as an additional analgesic when MAP increased by more than $20 \%$ of control values, and isoflurane concentrations were decreased when MAP fell by more than 20\%, whereupon $10 \mathrm{mg}$ ephedrine was administered IV. Atropine sulfate $(0.5 \mathrm{mg})$ was given by IV 
and the isoflurane concentration decreased if the heart rate fell below $50 \mathrm{bpm}$. When necessary to ensure equivalent anesthesia depth, the volatile agent was increased by 0.2-0.25.

For nausea and vomiting prophylaxis, we gave ondansetron (4 mg) by IV and for postoperative pain control, we administered $75 \mathrm{mg}$ diclofenac sodium intramuscularly in all patients 30 minutes before the operation's end. The bleeding rate was determined by the surgeon according to the Fromm-Boezaart Quality Scale where: "0", no bleeding; “1"- there was no need to remove blood from the surgical field; " 2 "- sometimes there was the need to remove blood from the surgical field; " 3 " blood was removed from the operation area frequently; "4" the field could be visualized only upon blood removal; " 5 "- bleeding did not allow continuation of the operation. In addition, surgeon satisfaction was assessed and recorded as: "good" = 1; "average" = 2; "bad" = 3 .

For calculating gas consumption, we performed a repetitive calibration process of the anesthesia device for each patient. At the end of the operation, we recorded the total amount of isoflurane, $\mathrm{N}_{2} \mathrm{O}$, and $\mathrm{O}_{2}$ consumed through calculations made by the ADU S/5 anesthesia device. In addition, the amount of dexmedetomidine and additional medicine consumed was also recorded. Complications such as nausea, vomiting, itching and urine retention occurring during the postoperative period were also recorded.
The SPSS 13 package program was used to evaluate data obtained in this study. Normality analysis of data was performed by the Shapiro-Wilk test. Student's $t$-test was used in independent groups for the data showing normal distribution and the Chi-Square test was used for the variables calculated on a categorical basis. $P$ values $<0.05$ were considered statistically significant. The patients who participated in the study were randomly determined and a neutrality assumption was achieved. Before this study, the effect size of $0.85, \alpha=0.05$ and theoretical power $(1-B)=0.70$ values were accepted and using the Gpower package program the study was performed with 40 subjects where $\mathrm{n} 1=\mathrm{n} 2=20$.

\section{Results}

The study groups were matched according to age (year), weight, height, operation period, gender, and ASA scores ( $p>0.05$ ) (Table 1 and 2).

Hemodynamic data showed that in each group heart rates decreased after dexmedetomidine loading. After intubation, both groups had the same rate of heart rate increase to return to or slightly exceed basal values. After intubation, Group A had a lower heart rate decrease between 5 and 30 minutes after intubation ( $p<0.05$; Student's t-test) (Figure 1).

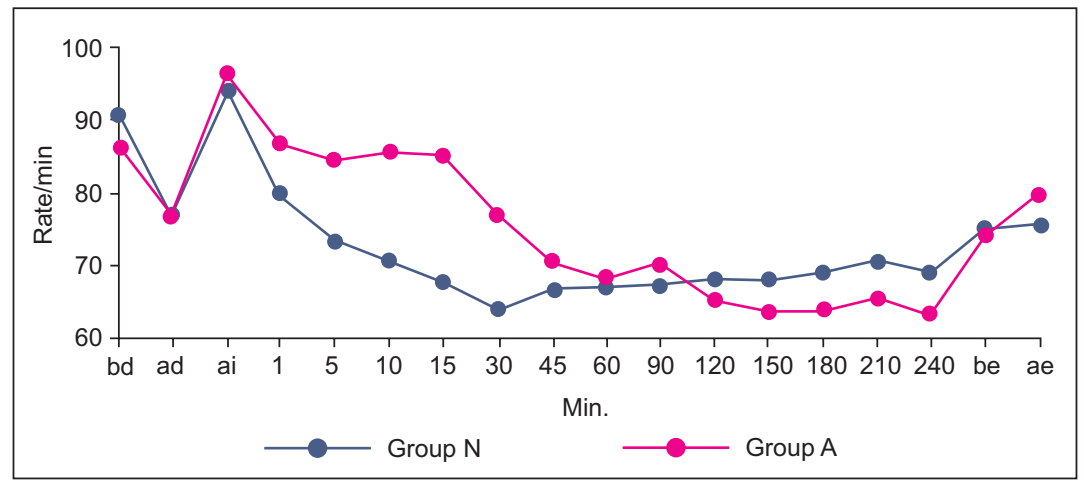

Figure 1 Heart rate distribution.

bd: dexmedetomidine before, ad: after dexmedetomidine loading, ai: after intubation, be: before extubation, ae: after extubation.

Table 1 Student's $t$-test results and comparison of patient characteristics.

\begin{tabular}{llll}
\hline & $\begin{array}{l}\text { Group N } \\
(\mathrm{n}=20)\end{array}$ & $\begin{array}{l}\text { Group A } \\
(\mathrm{n}=20)\end{array}$ & $\mathrm{p}^{+}$ \\
\hline Age (years) & $30.5 \pm 8.90$ & $34.05 \pm 10.27$ & 0.278 \\
Weight (kg) & $65.12 \pm 13.45$ & $72.40 \pm 14.49$ & 0.088 \\
Height (cm) & $165.93 \pm 5.57$ & $169.27 \pm 8.70$ & 0.064 \\
Operation Period (min) & $168.12 \pm 59.41$ & $156.75 \pm 58.49$ & 0.588 \\
\hline
\end{tabular}

Average \pm Standard Deviation; ${ }^{+} t$-test in independent groups.

Table 2 Comparison of patient characteristics and Chi-Square test results.

\begin{tabular}{llll} 
& $\begin{array}{l}\text { Group N } \\
(n=20)\end{array}$ & $\begin{array}{l}\text { Group A } \\
(n=20)\end{array}$ & $\begin{array}{l}\text { P } \\
\text { (Chi Square) }\end{array}$ \\
\hline Gender (F / E) & $15 / 5$ & $9 / 11$ & 0.074 \\
ASA I / II & $8 / 12$ & $4 / 16$ & 0.130 \\
\hline
\end{tabular}

${ }^{*} p<0.05$. 


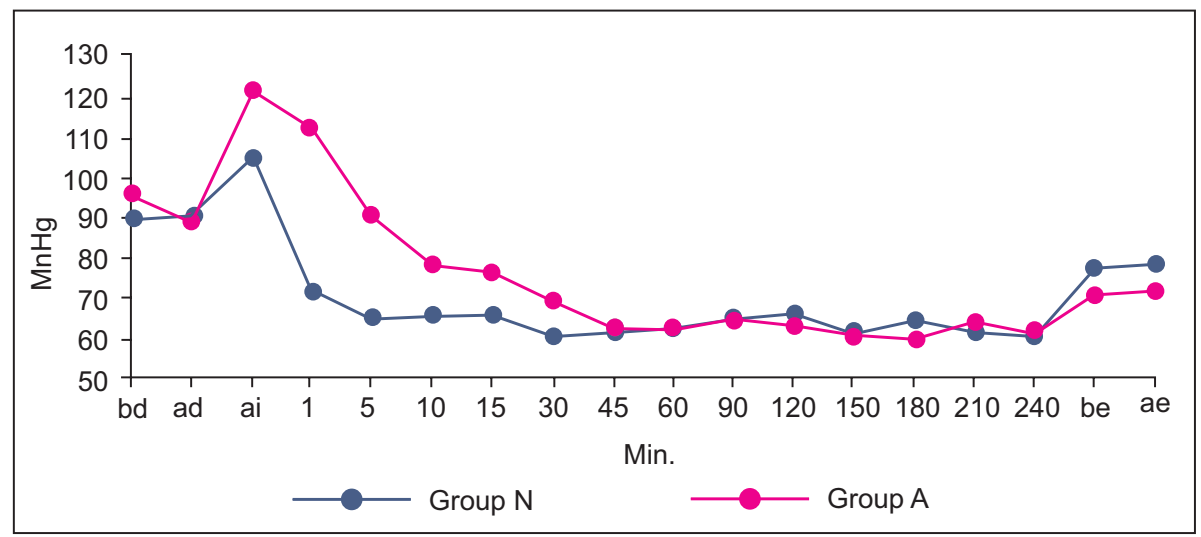

Figure 2 MAP distribution.

bd: dexmedetomidine before, ad: after dexmedetomidine loading, ai: after intubation, be: before extubation, ae: after extubation.

There was no significant difference in MAP for each group after dexmedetomidine loading. After intubation, MAP was higher for minutes 1-15 for Group A ( $<$ 0.05) (Figure 2). Group N reached desired hypotension levels five minutes after intubation, while Group A reached desired levels 20 minutes after intubation. Although we stopped dexmedetomidine in the last 30 minutes, MAP remained similar before and after intubation (Figure 2).

Beginning just after intubation, Group N's MAC values were slightly higher than Group A's, with differences at minutes one, three, five, 10, and 15 (Figure 3$)(p<0.05)$.

Group $\mathrm{N} \mathrm{FiO}_{2}$ values were lower than Group A, although no group had values that fell by more than $30 \%$ during any interval. While Group $\mathrm{A} \mathrm{FiO}_{2}$ values were higher between five and 60 minutes, by minute 90 Group $\mathrm{N}$ had higher values $(p<0.05)$. Between 150 and 240 minutes, values were again higher in Group A, albeit with no statistically significant difference (Figure 4) $(p<0.05)$.

$\mathrm{Fi}$ Iso values were lower in Group N compared to Group A, starting at 15 minutes. There were statistical differences between the values at minute 15 and 30 (Figure 5). The groups showed no difference between ETIso and $\mathrm{ETCO}_{2}$ pressures or P plateau values.
There was no significant difference between groups with respect to dexmedetomidine $(\mathrm{mcg})$, isoflurane $(\mathrm{mL})$ and Alfentanil (mcg) values. While the dexmedetomidine and isoflurane usage was higher for Group A, the difference was not significant (Table 3 ).

We did not have to increase the gas flow, since no decrease in oxygen saturation and $\mathrm{FiO}_{2}$ values below 94 or $30 \%$, respectively, occurred, and there were no $\mathrm{ETCO}_{2}$ values over $40 \mathrm{~mm} \mathrm{Hg}$. Alfentanil (7 $\left.\mu \mathrm{g} . \mathrm{kg}^{-1}\right)$ was used intravenously for three and four patients in Groups $\mathrm{N}$ and $\mathrm{A}$, respectively, because the MAP fell below desired values. At other time points there was no significant difference between the groups in terms of these data. $(p<0.05)$.

At minute 15, during which time surgical incisions occurred, bleeding with a score of one as per the FrommBoezaart Quality Scale was observed for six Group N patients and eight Group A patients. There were no differences between the groups for other findings or surgeon satisfaction.

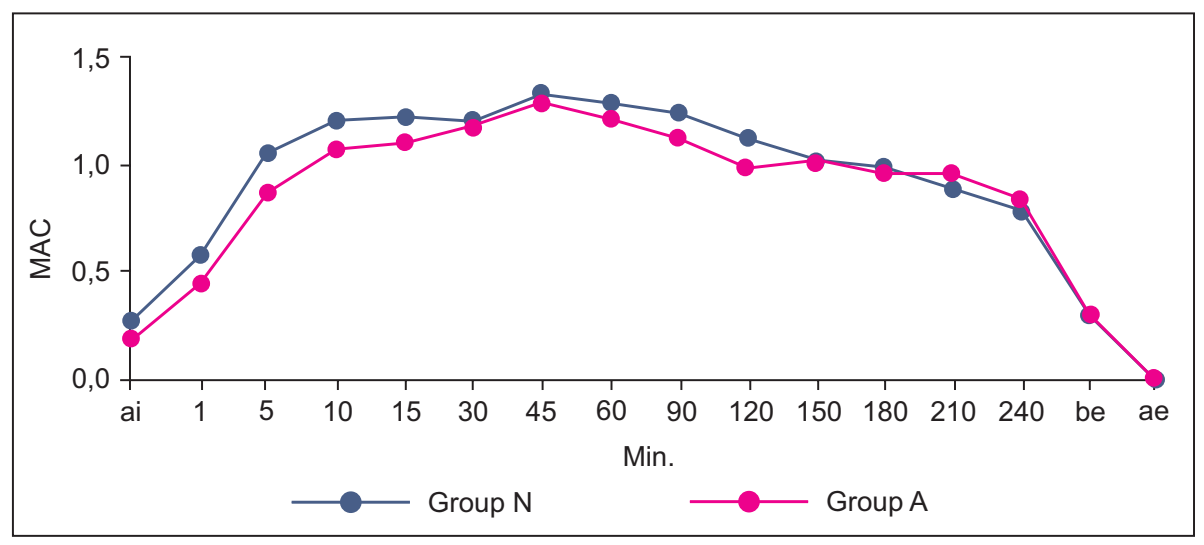

Figure 3 MAC distribution.

ai: after intubation, be: before extubation, ae: after extubation. 


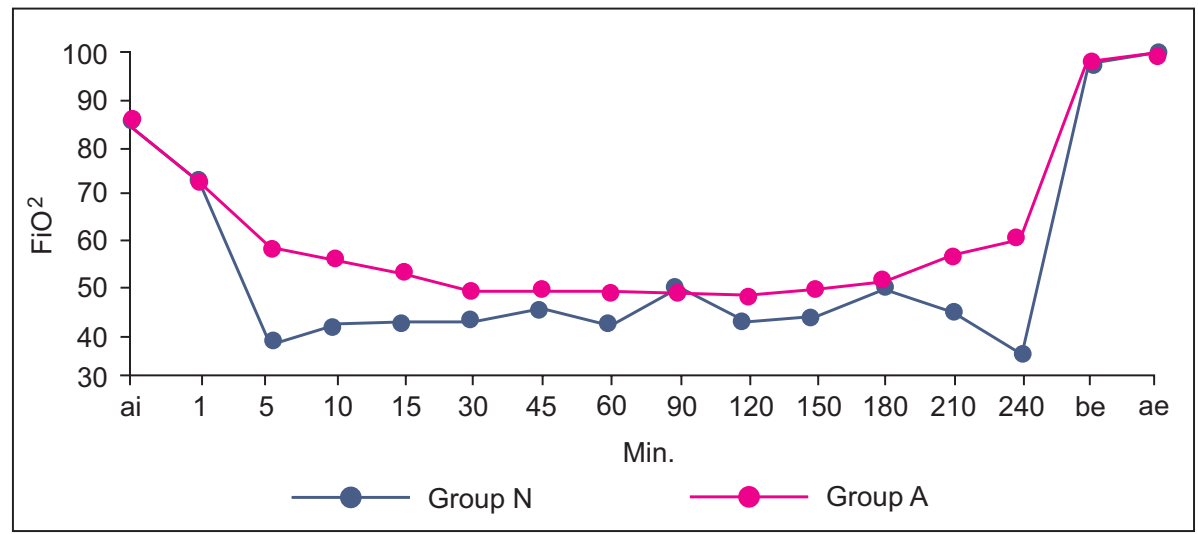

Figure $4 \mathrm{FiO}_{2}$ distribution. ai: after intubation, be: before extubation, ae: after extubation.

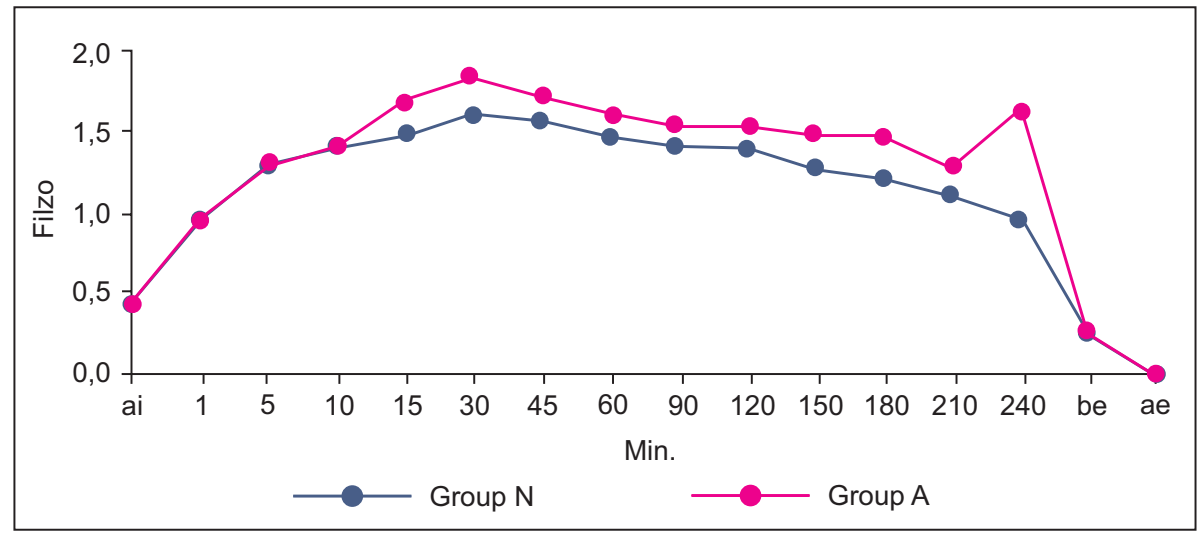

Figure 5 Fi Iso distribution.

ai: after intubation, be: before extubation, ae: after extubation.

Table 3 Medicine consumption.

\begin{tabular}{llll}
\hline & Group N $(\mathrm{n}=20)$ & Group A $(\mathrm{n}=20)$ & $\mathrm{p}^{+}$ \\
\hline Dexmedetomidine $(\mathrm{mcg})$ & $168.12 \pm 51.53$ & $174.55 \pm 56.66$ & 0.756 \\
Isoflurane $(\mathrm{mL})$ & $21.25 \pm 13.72$ & $24.16 \pm 7.17$ & 0.070 \\
Alfentanil $(\mathrm{mcg})$ & $0.18 \pm 0.40$ & $0.22 \pm 0.42$ & 0.806 \\
\hline
\end{tabular}

Average $\pm \mathrm{SS} ;{ }^{+} t$-test in independent groups.

\section{Discussion}

The major risks in low flow anesthesia application include hypoxia, use of volatile anesthetics at low or high dosages, development of hypercapnia and accumulation of toxic trace gases ${ }^{12}$. Low flow anesthesia methods are recommended for minor and average operations and for patients without significant complaints at the outset. For this reason, class ASA I or II patients were selected.

When applying low flow methods, devices that can monitor and carefully adjust the alarm limit values of air line pressure, the gas volume inhaled, $\mathrm{FiO}_{2}$, concentration of volatile anesthetic agent and $\mathrm{CO}_{2}$ concentrations should be used ${ }^{12}$. Here, the ADU S/5 (Datex- Ohmeda ${ }^{\circledR}$ ) anesthesia device was used, which allows monitoring of these values and electronic control of fresh gas flow.

In the low flow anesthesia method, there is an initial time period of 6-8 minutes for high flows of fresh gas (4-5 L. $\left.\mathrm{min}^{-1}\right)$, which fills the system and adjusts the patient's functional residual capacity, actualizes $\mathrm{N}_{2} \mathrm{O}$ equalization, and allows sufficient anesthesia depth by providing denitrogenization. Afterwards, the fresh gas flow rate is decreased to $1 \mathrm{~L} \cdot \mathrm{min}^{-1}$ and low flow anesthesia is initiated ${ }^{12}$. Here, we started the low flow anesthesia application after 10 minutes of denitrogenization. 
In our study we observed a decrease in hemodynamic data before the operation following dexmedetomidine loading, although these values returned to baseline values after intubation (even when calculated hemodynamic values were high for the group without nitrous oxide, sufficient anesthesia depth and controlled hypotension was achieved). In terms of medicine usage, bleeding, and surgeon satisfaction, no difference was found between groups. These findings are in agreement with those of other studies ${ }^{13}$.

The development of anesthesia devices, increased environmental sensitivity awareness, anesthetics with new features and high costs, coupled with the financial limitations of the medical sector worldwide led to the use of low flow anesthesia methods ${ }^{14}$. In low flow anesthesia, the air exhaled after $\mathrm{CO}_{2}$ absorption, which is used in half-closed systems, is re-exhaled to the patient in ratios of at least $50 \%$. This situation can be achieved by modern re-inhalation systems only if fresh gas flow can be decreased 2.0 L. dk ${ }^{-1}{ }^{15}$. According to the studies, high gas flow in the initial phase, which lasts 10 minutes, is obligatory to ensure that flow rates will be at least $30 \%$ for $\mathrm{FiO}_{2}, 3.0$ L. min $^{-1}$ for $\mathrm{N}_{2} \mathrm{O}$ flow and $1.4 \mathrm{~L}$. min ${ }^{-1}$ for oxygen flow ${ }^{16}$. The isoflurane dose should be adjusted to $1.5 \%$ during this initial phase. If these adjustments are made in the first 10 minutes, the general MAC will be 1.3. In our study, the MAC value for the group with nitrous oxide was similar to this value. This value is $A D_{95}$ and is accepted as sufficient anesthesia depth that guarantees that $95 \%$ of patients won't react to a skin incision. Aantaa et al. ${ }^{17}$ reported that dexmedetomidine used in high dosages decreases isoflurane MAC to $47 \%$. These low MAC values can produce hypotension at desired levels with lower isoflurane concentrations resulting from dexmedetomidine usage in both groups.

By decreasing the flow in low flow anesthesia, an increase could be observed in $\mathrm{FiO}_{2}$ between 30 and 45 minutes with a continuous and slow decrease following this baseline increase. When the oxygen alarm limit is reached, oxygen flow rate must be increased and $\mathrm{N}_{2} \mathrm{O}$ must be decreased in same ratio. In our study no patient experienced a decrease under $30 \%$ for $\mathrm{FiO}_{2}$, probably because $50 \%$ oxygen was used in our low flow application.

Although Tobias and Berkenbosch ${ }^{13}$ state that after stopping dexmedetomidine infusion patients' hemodynamic parameters returned to basal values within 7 minutes, in our study this period continued after extubation. If low flow anesthesia were maintained, this prolongation would be expected since the decrease in anesthetic concentrations is slow and late. Also, the reported isoflurane concentration was lower than those used here.

Isoflurane is believed to be the most suitable volatile anesthetic for creating hypotension in healthy patients ${ }^{18}$. In studies on both humans and animals, isoflurane was shown to decrease blood pressure by decreasing vascular resistance ${ }^{19,20}$. Macnab et al. ${ }^{21}$ stated that MAP could be decreased efficiently and the stress response weakened when isoflurane was used in cerebral aneurysm surgery. The limit value of blood flow that creates ischemia for patients undergoing carotid endarterectomy is lower for isoflurane compared to enflurane and halothane. Newman et al. ${ }^{22}$ stated that for cerebral aneurysm clips applied to patients, isoflurane has beneficial effects on the cerebral oxygen presentation-requirement ratio. Haraldsted et al. ${ }^{23}$ also stated that the maximum limit of MAC value at which these beneficial effects were seen is 2.5.

Madsen et al. ${ }^{6}$ reported that rebound hypertension occurs after stopping isoflurane for cerebral aneurysm clips applied to patients and isoflurane alone could not prevent sympathetic stimulation with rebound hypertension prevented by the $\mathrm{a}_{2}$-agonist clonidine. Also, because isoflurane does not completely block baroreceptor reflexes, it can obstruct rebound sympathetic stimulation to reach desired hypotension levels and resistance can develop against the hypertensive effects of isoflurane ${ }^{6}$. The combination of isoflurane with agents to maintain cardiac output will be more suitable than using it alone in higher dosages ${ }^{24}$. Toivenen and Kaukinen evaluated the ability of clonidine to decrease the use of hypertensive agents in middle ear surgery and found that clonidine premedication at 4-5 $\mu \mathrm{g} . \mathrm{kg}^{-1}$ decreased the usage of labetalol or isoflurane in hypotension while also preventing increases in plasma catecholamine levels and causing the subsequent development of rebound hypertension ${ }^{7}$. Woodcock et al. ${ }^{8}$ administered clonidine premedication $(0.6 \mathrm{mg}$ oral) with isoflurane $(2 \%)$ to middle ear and nasal surgery patients 2 hours before surgery and then tried to achieve hypertensive anesthesia by administering 3\% isoflurane. The premedication decreased the amount of hypotensive needed and the isoflurane amount required to obtain hypotension was also decreased.

The combination of isoflurane with medicines that block a-adrenergic or B-adrenergic receptors decreases the negative effects compared to single use of isoflurane as a hypertensive ${ }^{25,26}$. Thus, isoflurane should be used as adjuvant medicine in low concentrations while using controlled hypertension. This method has advantages such as decreasing cerebral metabolism and protecting pulmonary gas exchange ${ }^{27}$.

Dexmedetomidine is a specific $a_{2}$-adrenoceptor agonist. In addition to being generally used in mechanical ventilation of adults, it is frequently used after cardiac surgery as a sedative. The anxiolytic and anesthetic characteristics and its ability to enhance the effects of opioids make dexmedetomidine a part of a balanced anesthetic management. Dexmedetomidine also could be beneficial for hypotension because it decreases average artery pressure and heart rate ${ }^{13}$. Premedication with dexmedetomidine at 1.2-2.5 $\mu \mathrm{g} . \mathrm{kg}^{-1}$ dosages inhibits the cardiovascular response at laryngoscopy and tracheal intubation ${ }^{28}$. Intravenous dexmedetomidine $\left(0.6 \mu \mathrm{g} . \mathrm{kg}^{-1}\right)$ given 10 minutes before anesthesia induction decreases the stress response ${ }^{29}$. Compatible with results obtained with normotensive patients, the stress response to laryngoscopy and endotracheal intubation was also suppressed when dexmedetomidine was administered 10 minutes before anesthesia.

In middle ear surgery, disruption of intra-operative vision due to bleeding is a serious problem. Ülger et al. ${ }^{10}$ reported that dexmedetomidine enables better surgical vision and exposure compared to nitroglycerine not only by decreasing blood pressure, but also by enhancing capillary blood flow and venous pressure. In our evaluations, Group N (with nitrous oxide) had bleeding in six patients as compared to eight patients in Group A. Membrane placement in tympanoplasty 
operations generally occurs between minute 60 and 100 and takes approximately 20 to 30 minutes. During this time period, both groups had bleeding scores of zero and desired average artery pressures. Together, these results indicate that the hypotension level achieved is sufficient and that dexmedetomidine is effective for controlled hypotension.

During tympanoplasty, the middle ear is open to the atmosphere and there is no pressure increase. When the tympanic membrane is placed, the middle ear again becomes a closed space. If nitrous oxide diffuses to this space, pressure in the middle ear will be increased and the membrane could detach from its placement site. If the nitrous oxide flow is stopped after membrane placement, a negative pressure could develop and the membrane may collapse from within. For both reasons, nitrous oxide should either be avoided during tympanoplasty or stopped before graft placement ${ }^{10}$.

Low flow anesthesia methods minimize problems such as release of nitrous oxide to the atmosphere and operating room contamination ${ }^{30-32}$, while maintaining the amount of gas received by patients and keeping harmful results unchanged. To prevent these problems, the use of nitrous oxide should be avoided in all inhalation anesthesia administrations, including low flow anesthesia methods. Analgesia loss arising from stopping nitrous oxide flow could be compensated by opioid usage and hypnotic effect loss could be compensated by increasing volatile agent concentration ${ }^{12,13}$.

In conclusion, in low flow anesthesia for middle ear surgery the desired mean arterial pressure could be achieved in both groups by using isoflurane and dexmedetomidine although the desired mean arterial pressure was reached later for the group without nitrous oxide. However, during surgical membrane placement that occurs in the last phases of the operation, the surgeon would not be affected by this delay, making dexmedetomidine a suitable agent to provide controlled hypotension without nitrous oxide in middle ear surgery.

\section{References}

1. Van Aken H, Miller Jr ED - Deliberate hypotension. In: Miller RD(ed). Anesthesia. Fifth edition. New York: Churchill Livingstone; 2000;1470-1490.

2. Degoute CS, Dubreuil C, Ray MJ, et al. - Effects of posture, hypotension and locally applied vasoconstriction on the middle ear microcirculation in anaesthetized humans. Eur J Appl Physiol. 1994;69:414-420.

3. Boezaart AP, van der Merwe J, Coetzee AR - Comparison of sodium nitroprusside-and esmolol-induced controlled hypotension for functional endoscopic sinus surgery. Can J Anaesth. 1995;42:373-376.

4. Pilli G, Güzeldemir ME, Bayhan N - Esmolol for hypotensive anesthesia in middle ear surgery. Acta Anaesthesiol Belg. 1996;47:85-91.

5. Pavlin JD, Colley PS, Weymuller EA Jr et al. - Propofol versus isoflurane for endoscopic sinus surgery. Am J Otolaryngol. 1999;20:96-101.

6. Madsen JB, Cold GE, Hansen ES, Bardrum B, Kruse-Larsen C Cerebral blood flow and metabolism during isoflurane-induced hypotension in patients subjected to surgery for cerebral aneurysms. Br J Anaesth. 1987;59: 1204-1207.

7. Toivonen J, Kaukinen S - Clonidine premedication: a useful adjunct in producing deliberate hypotension. Acta Anaesth Scand. 1990;34:653-357.
8. Woodcock TE, Millard RK, Dixon J, Prys-Roberts C - Clonidine premedication for isoflurane-induced hypotension. Sympathoadrenal responses and a computer-controlled assessment of the vapour requirement. $\mathrm{Br} J$ Anaesth. 1988;60:388-394.

9. Aho M, Lehtinen AM, Erkola O, Kallio A, Korttila K - The effect of intravenously administered dexmedetomidine on perioperative hemodynamics and isoflurane requirements in patients undergoing abdominal hysterectomy. Anesthesiology. 1991;74:997-1002.

10. Ülger HM, Demirbilek S, Köroğlu A, Borazan H, Ersoy MÖ - Orta kulak cerrahisinde dexmedetomidin ile kontrollü hipotansiyon. İnönü Üniversitesi Tıp Fakültesi Dergisi. 2004;11:237-241.

11. Imberti R, Preseglio I, Imbriani M, Ghittori S, Cimino F, Mapelli A - Low flow anaesthesia reduces occupational exposure to inhalation anaesthetics. Acta Anaesthesiol Scand. 1995;39:586591.

12. Baum JA - Low flow anaesthesia in clinical practice. In: Baum JA (ed). Low Flow Anaesthesia. The theory and practice of low flow, minimal flow and closed system anaesthesia (2nd ed). Oxford, Butterworth Heinemann. 2001;220-268.

13. Tobias JD, Berkenbosch JW - Initial experience with dexmedetomidine in paediatric-aged patients. Paediatr Anaesth. 2002;12:171-175.

14. Baxter $A D$ - Low and minimal flow inhalation anaesthesia. Can J Anaesth. 1997;44:643-653.

15. Baum JA, Aitkenhead AR - Low-flow anaesthesia. Anaesthesia. 1995;50(Suppl):37-44.

16. Barton F, Nunn JF - Totally closed circuit nitrous oxide/oxygen anaesthesia. Br J Anaesth. 1975;47(3):350-357.

17. Aantaa R, Jaakola M-L, Kallio A, Kanto J - Reduction of the Minimum Alveolar Concentration of Isoflurane by Dexmedetomidine. Anesthesiology. 1997;86:1055-1060.

18. Bertrand D, Boivin G, Manel J, Laxenaire MC - Effects of isoflurane on bleeding in microsurgery of the middle ear. Ann Fr Anesth Reanim. 1987;6:416-418.

19. Lam AM, Gelb AW - Cardiovascular effects of isoflurane-induced hypotension for cerebral aneurysm surgery. Anesth Analg. 1983;62:742-748.

20. Van Aken H, Fitch W, Graham DI, Brüssel T, Themann H - Cardiovascular and cerebrovascular effects of isofluraneinduced hypotension in the baboon. Anesth Analg. 1986;65:565574.

21. Macnab MS, Manninen PH, Lam AM, Gelb AW - The stress response to induced hypotension for cerebral aneurysm surgery: a comparison of two hypotensive techniques. Can J Anaesth. 1988;35:111-115.

22. Newman B, Gelb AW, Lam AM - The effect of isoflurane-induced hypotension on cerebral blood flow and cerebral metabolic rate for oxygen in humans. Anesthesiology. 1986;64:307-310.

23. Haraldsted VY, Asmussen J, Herlevsen P, Cold GE - Cerebral arteriovenous difference of oxygen during gradual and sudden increase of the concentration of isoflurane for induction of deliberate hypotension. Acta Anaesthesiol Scand. 1992;36:142144.

24. Dal D, Çeliker V, Özer E, Başgül E, Salman MA, Aypar Ü - Induced hypotension for tympanoplasty: a comparison of desflurane, isoflurane and sevoflurane. Eur J Anaesthesiol. 2004;21:902906.

25. Kick O, Van Aken H, Wouters PF, Verbesselt K, Van Hemelrijck $\mathrm{J}$ - Vital organ blood flow during deliberate hypotension in dogs. Anesth Analg. 1993;77:737-742.

26. Toivonen J, Virtanen $\mathrm{H}$, Kaukinen S - Labetalol attenuates the negative effects of deliberate hypotension induced by isoflurane. Acta Anaesthesiol Scand. 1992;36:84-88. 
27. Nicholas JF, Lam AM - Isoflurane-induced hypotension does not cause impairment in pulmonary gas exchange. Can Anaesth Soc J. 1984;31:352-358.

28. Aantaa R, Jaakola ML, Kallio A, Kanto J, Scheinin M, Vuorinen $\mathrm{J}$ - A comparison of dexmedetomidine, and alpha 2-adrenoceptor agonist, and midazolam as i.m. premedication for minor gynecological surgery. Br J Anaesth. 1991;67:402-409.

29. Jaakola ML, Ali-Melkkilä T, Kanto J, Kallio A, Scheinin H, Scheinin $M$ - Dexmedetomidine reduces intraocular pressure, intubation responses and anaesthetic requirements in patients undergoing ophthalmic surgery. Br J Anaesth. 1992;68:570-575.
30. Watts A, Luney SR, Lee D, Gelb AW - Effect of nitrous oxide on cerebral blood flow velocity after induction of hypocapnia. $\mathrm{J}$ Neurosurg Anaesthesiol. 1998;10:142-145.

31. Morgan GE, Mikhail MS, Murray MJ, Larson CP - Clinical Anesthesiology. Third Edition. Lange; 2001;143.

32. Bozkurt P, Saygı NE, Tomatır E, Yeker Y - N2O-free low-flow anesthesia technique for children. Acta Anaesthesiol Scand. 2005;49:1330-1333. 